\title{
Entropy Generation Analysis on MHD Flow with a Binary Mixture of Ethylene Glycol and Water Based Silver-Graphene Hybrid Nanoparticles in Automotive Cooling Systems
}

\author{
Seethi Reddy R. Reddy, Polu Bala Anki Reddy* \\ Department of Mathematics, SAS, Vellore 632014, Tamil Nadu, India
}

Corresponding Author Email: bala.anki@vit.ac.in

https://doi.org/10.18280/ijht.390611

Received: 13 September 2019

Accepted: 15 April 2021

\section{Keywords: \\ entropy generation, hybrid nanoparticles, joule heating, $M H D$, silver-graphene nanoparticles, stagnation point}

\begin{abstract}
The present work is focused on the flow and transfer of heat analysis of the silver-graphene with a binary mixture of ethylene glycol (EG) and water $(0: 100,20: 80$ and 40:60 vol \%) based hybrid nanofluids. Flow formulation is developed by considering the effect of magnetic field, stagnation point flow, Joule heating and viscous dissipation. Heat exchanger plays an important role because of the increasing demand for efficient cooling systems in automotive industries. Proper transforms lead to highly nonlinear differential systems, which are solved through shooting procedure with fourth order R-K (RungeKutta) method. The results of numerous control parameters for both silver-graphene nanoparticles are graphically shown and discussed in detail. The current numerical work is qualified through comparative study with the formerly published results for a special case. The heat transfer rate is higher with lower $E c$ values and higher $\phi_{1}$ and $\phi_{2}$ values.
\end{abstract}

\section{INTRODUCTION}

Conventional heat transfer fluids found to have less transfer of heat owing to their poorer thermal conductivity related to metals. These fluids are EG, water, lubricant oil and kerosene oil etc. Choi and Eastman [1] found that adding nanoparticles to the base fluids could increase its thermal conductivity and result in improved heat transfer. Using the Maxwell-Garnett model, Turkyilmazoglu [2] studied the effects of dissimilar nanoparticles of $\mathrm{TiO}_{2}, \mathrm{CuO}, \mathrm{Cu}, \mathrm{Ag}$ and $\mathrm{Al}_{2} \mathrm{O}_{3}$ with pure water on the flow and heat behaviour of a traditional laminar plane wall jet. Akbar et al. [3] used the Cattaneo-Christov heat flux model for the transfer of heat through SWCNT and MWCNT nanofluids in a permeable stretching surface. The effect of variable thermal conductivity on hydromagnetic kerosene alumina nano-liquid was examined by Ellahi et al. [4]. In many studies [5-9], the effect of MHD flow of aluminum alloys, copper, titanium alloy with different base fluids have been discussed.

However, there has recently been little work on nanofluid with disparate nanoparticles simultaneously dispersed in a base fluid called hybrid nanofluids. These hybrid nanofluids are a new group of nanofluids that have almost all applications in heat transfer fields such as defence, medical, manufacturing, acoustics, microfluidics, microelectronics, transport, naval structures, propulsion, automotive engine and so on. Ma et al. [10] presented the effect of MHD on $\mathrm{Ag}-\mathrm{MgO} /$ water hybrid nanofluid in a channel. Iqbal et al. [11] analyzed the performance of $\mathrm{Cu}-\mathrm{CuO} /$ water hybrid nanofluid on MHD rotating transport in rotating vertical channel. Platelets, brick and cylinder-shaped nanoparticles were used for accelerating fluid flow. They reported that brick-shaped nanoparticles are very effective for temperature efficiency. Sajjadi et al. [12] were used the MWCNT-Fe ${ }_{3} \mathrm{O}_{4} /$ water hybrid nanofluid to investigate the effect of nanoparticle on heat transfer. There have been some reports of hybrid nanoparticles on different geometries [13-20].

Generally, nanoparticles are made of carbon nanotubes, carbides, oxides, graphene and metal, and the base fluids are glycol, water, engine oil etc. In nanoparticles, silver and graphene are the most important nanomaterials. Graphene particles have higher thermal conductivity, highest electron mobility of all electronic materials, lowest electrical resistivity and also higher mechanical strength [21]. In addition, graphene is very easy and inexpensive to synthesize nanoparticles. Bahiraei and Heshmatian [22] investigate the efficiency and entropy production of a hybrid nanofluid containing graphene nano platelets decorated with silver nanoparticles in three different liquid blocks for CPU cooling. Nowadays, anti-freeze fluids (a mixture of ethylene glycol and water-ethylene glycol) are mostly used in automobile radiators to avoid winter freezing.

Ethylene glycol, propylene glycol and water are usually taken as single base liquids in nanofluids, but the combination of the two liquids has the advantage of two pure compounds. The combination of the two liquids has a lower freezing point than water and higher thermal conductivity than pure glycol $[23,24]$. Therefore, useful applications of glycol-water areas transfer media in antifreeze or solar heating installations in car engines [25].

No work has been reported using dispersed silvergraphene/EG-water hybrid nanoparticles on MHD flow past over an upper horizontal surface of a paraboloid of revolution. Silver-graphene/EG-water hybrid nanofluid are widely used in cold areas for heat exchangers in cars, industrial coolants [26, 27], hyperthermia and many electronic devices in engineering [28]. In reality, stretching surface brings a unidirectional inclination to extrude, thereby considerably improving the final product quality, which is extremely dependent on mechanisms for flow and heat transfer. Glass blowing, wire drawing, continuous casting, and spinning of fibres also have a flow due to the stretched surface [29-35]. 


\section{MATHEMATICAL FORMULATION}

The present work explores the entropy optimization and Bejan number in hydromagnetic flow of EG and water mixture-based silver-graphene hybrid nanofluid flow past over an upper horizontal surface of a paraboloid of revolution (see Figures 1(a) and 1(b)). Influences of viscous dissipation with Joule heating are considered. Moreover, the upper paraboloid of revolution flow constructed with magnetic field $B(x)$ and stagnation point flow. We assume $y=J(x+c)^{0.5(1-\mathrm{n})}$ where $n$ represents velocity power index parameter $(n=1$ is flat sheet, $n<1$ is outer convex and $n>1$ inner convex shape). The governing boundary-layer equations for hybrid nanofluid past upper paraboloid of revolution can be written as (Das and Chatterjee [31], Pakravan and Yaghoubi [35], Pal and Mondal [34]).

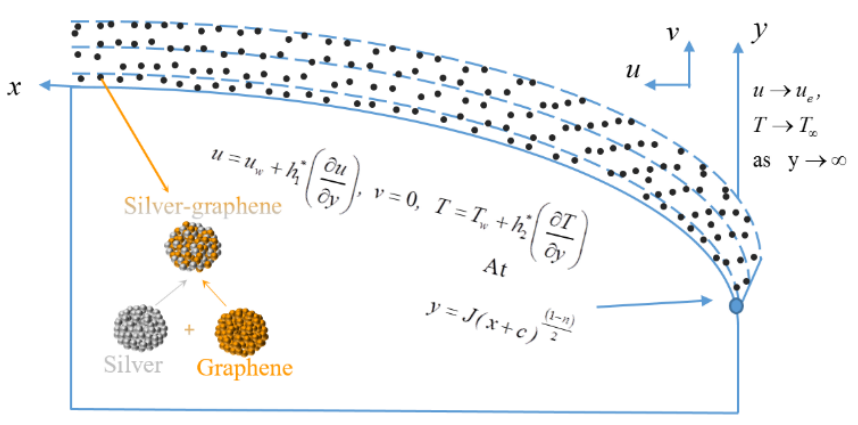

(a). Geometry of the problem

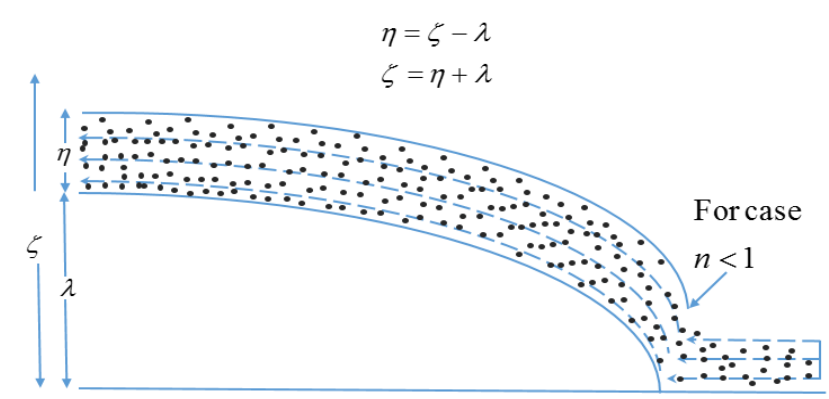

(b). Graphical illustration of fluid domain and conversion of domain $[\lambda, \infty]$ to $[0, \infty]$

Figure 1. Physical configuration of the problem

$$
\begin{gathered}
\frac{\partial u}{\partial x}+\frac{\partial v}{\partial y}=0 \\
u \frac{\partial u}{\partial x}+v \frac{\partial u}{\partial y}=v_{h n f} \frac{\partial^{2} u}{\partial y^{2}}+g\left(\beta_{T}\right)_{h n f}\left(T-T_{\infty}\right) \\
+u_{e} \frac{d u_{e}}{d x}+\frac{\sigma B^{2}}{\rho_{h n f}}\left(u_{e}-u\right) \\
u \frac{\partial T}{\partial x}+v \frac{\partial T}{\partial y}=\alpha_{h n f} \frac{\partial^{2} T}{\partial y^{2}}+\frac{\mu_{h n f}}{\left(\rho c_{p}\right)_{h n f}}\left(\frac{\partial u}{\partial y}\right)^{2} \\
+\frac{\sigma B^{2}}{\left(\rho c_{p}\right)_{h n f}}\left(u-u_{e}\right)^{2}
\end{gathered}
$$

The boundary conditions are

$$
\begin{aligned}
& u=u_{w}+h_{1}^{*}\left(\frac{\partial u}{\partial y}\right), v=0, \\
& T=T_{w}+h_{2}^{*}\left(\frac{\partial T}{\partial y}\right), \text { at } y=J(x+c)^{0.5(1-n)}, \\
& u \rightarrow u_{e}, T \rightarrow T_{\infty}, \text { as } y \rightarrow \infty .
\end{aligned}
$$

where,

$$
\begin{aligned}
& h_{1}^{*}=\left(\frac{2-f_{1}}{f_{1}}\right) \xi_{1}\left((x+c)^{(1-n)}\right)^{0.5}, h_{2}^{*}=\left(\frac{2-b}{b}\right) \xi_{2}\left((x+c)^{(1-n)}\right)^{0.5}, \\
& \xi_{2}=\left(\frac{2 \gamma_{1}}{\gamma_{1}+1}\right) \frac{\xi_{1}}{\operatorname{Pr}}, B=B_{0}(x+c)^{(n-1) 0.5}, u_{w}=U_{0}(x+c)^{n}, \\
& v_{w}=U_{0}(x+c)^{n}, T_{w}=T_{\infty}+T_{0}(x+c)^{(1-n) 0.5}, u_{e}=u_{\infty}(x+c)^{n} .
\end{aligned}
$$

In the above expressions $u$ and $v$ are the components of velocities in $x$ and $y$ directions respectively, $T$ is the temperature of the fluid, $\mathrm{c}_{p}$ is the specific heat at constant pressure, $\alpha$ is the thermal diffusivity, $k_{c}$ is the chemical reaction rate, $T_{0}$ are the reference temperature of fluid, $\mathrm{T}_{\infty}$ are the temperature of the ambient fluid. $\mathrm{h}_{1}{ }^{*}$ is the dimensional velocity slip variable, $\mathrm{h}_{2}{ }^{*}$ is the dimensional temperature jump variable, $f_{l}$ is the Maxwell's reflection coefficient, $b$ is the thermal accommodation coefficient, $\gamma_{1}$ is the ratio of specific heats, $\xi_{1} \xi_{2}$ are the constants (mean free path).

These nanofluid quantities are defined as:

$$
\begin{gathered}
\frac{\mu_{h n f}}{\mu_{f}}=\frac{1}{\left(1-\phi_{1}\right)^{2.5}\left(1-\phi_{2}\right)^{2.5}}, \alpha_{h n f}=\frac{k_{h n f}}{\left(\rho C_{p}\right)_{h n f}}, \\
\frac{\rho_{h n f}}{\rho_{f}}=\left(1-\phi_{2}\right)\left(\left(1-\phi_{1}\right)+\phi_{1} \frac{\rho_{s 1}}{\rho_{f}}\right)+\phi_{2} \frac{\rho_{s 2}}{\rho_{f}} \\
\frac{\left(\rho C_{p}\right)_{h n f}}{\left(\rho C_{p}\right)_{f}}=\left(1-\phi_{2}\right)\left(\left(1-\phi_{1}\right)+\phi_{1} \frac{\left(\rho C_{p}\right)_{s 1}}{\left(\rho C_{p}\right)_{f}}\right)+\phi_{2} \frac{\left(\rho C_{p}\right)_{s 2}}{\left(\rho C_{p}\right)_{f}} \\
\frac{\left(\rho \beta_{T}\right)_{h n f}}{\left(\rho \beta_{T}\right)_{f}}=\left(1-\phi_{2}\right)\left(\left(1-\phi_{1}\right)+\phi_{1} \frac{\left(\rho \beta_{T}\right)_{s 1}}{\left(\rho \beta_{T}\right)_{f}}\right)+\phi_{2} \frac{\left(\rho \beta_{T}\right)_{s 2}}{\left(\rho \beta_{T}\right)_{f}}, \\
\frac{k_{h n f}}{k_{b f}}=\frac{\left(1+2 \phi_{2}\right) k_{s 2}+2\left(1-\phi_{2}\right) k_{b f}}{\left(1-\phi_{2}\right) k_{s 2}+\left(2+\phi_{2}\right) k_{b f}}, \\
\frac{k_{b f}}{k_{f}}=\frac{\left(1+2 \phi_{1}\right) k_{s 1}+2\left(1-\phi_{1}\right) k_{f}}{\left(1-\phi_{1}\right) k_{s 1}+\left(2+\phi_{1}\right) k_{f}},
\end{gathered}
$$

where, $\mu_{h n f}$ is the dynamic viscosity of hybrid nanofluid, $\alpha_{h n f}$ is the thermal diffusivity of the nanofluid, $v_{h n f}$ is the kinematic viscosity of hybrid nanofluid, $k_{h n f}$ is the thermal conductivities hybrid nanoparticle, $(\rho \beta T)_{h n f}$ is the thermal expansion coefficient of hybrid nanofluid, $\left(\rho c_{\rho}\right)_{h n f}$ is the heat capacitance of the hybrid nanofluid, $\rho_{h n f}$ are the density of the hybrid nanofluid, $\phi_{1}$ volume fraction of $\mathrm{Ag}$ (silver) nanoparticle, $\phi_{2}$ volume fraction of Graphene nanoparticle, The suffices $\mathrm{f} \mathrm{s} 1$, s2, $f$ and hnf denote solid nanoparticles of silver, solid nanoparticles of Graphene, fluid, hybrid nanofluid respectively. The values of density $(\rho)$, specific heat $\left(C_{p}\right)$, thermal conductivity $(k)$ and thermal expansion coefficient $\left(\beta_{\mathrm{r}}\right)$ of base fluids and nanoparticles are given in Table 1 . We examined the verification of current code. According to Table 2 , good concordance can be found. 
Table 1. Density $(\rho)$, specific heat $\left(C_{p}\right)$, thermal conductivity $(k)$ and thermal expansion coefficient $\left(\beta_{T}\right)$ of base fluids and nanoparticles [24]

\begin{tabular}{cccccc}
\hline Physical properties & $\begin{array}{c}\text { 0:100\% } \\
\text { EG:Water }\end{array}$ & $\begin{array}{c}\mathbf{2 0 : 8 0 \%} \\
\text { EG:Water }\end{array}$ & $\begin{array}{c}\text { 40:60\% } \\
\text { EG:Water }\end{array}$ & Ag & Graphene \\
\hline$\rho\left(\frac{k g}{m^{3}}\right)$ & 997.1 & 1027.93 & 1057.60 & 10,500 & 2250 \\
$C_{p}\left(\frac{J}{k g K}\right)$ & 4180 & 3826 & 3485 & 235 & 2100 \\
$k\left(\frac{W}{m K}\right)$ & 0.613 & 0.498 & 0.408 & 429 & 2500 \\
$\beta_{T}\left(\frac{1}{K}\right)$ & $0.21 * 10^{-3}$ & $0.28 * 10^{-3}$ & $0.35^{*} 10^{-3}$ & $1.89 * 10^{-5}$ & $-7 * 10^{-6}$ \\
$P r$ & 6.07 & 11.21 & 21.95 & & \\
\hline
\end{tabular}

Table 2. Comparison of $-\theta$ '(0) for various $G r$ and $\operatorname{Pr}$ with previous work $[28,29]$ when $A=0, \phi_{1}, \phi_{2}=0, E c=0, M=0, \lambda=0$, $\tau_{1}=0 \quad \tau_{2}=0$, and $n=1$

\begin{tabular}{ccccc}
\hline $\boldsymbol{G} \boldsymbol{r}$ & $\boldsymbol{P r}$ & $\begin{array}{c}\text { Ishak et al. [29] } \\
\text { (Exact Sol.) }\end{array}$ & Pal [28] & $\begin{array}{c}\text { Present } \\
\text { results }\end{array}$ \\
\hline 0 & 0.72 & & 0.80863135 & 0.808631 \\
& 1.0 & 1.0000 & 1.00000000 & 1.000000 \\
& 3.0 & 1.9237 & 1.92368256 & 1.923683 \\
& 7.0 & & 3.07225020 & 3.072250 \\
& 10.0 & 3.7207 & 3.72067391 & 3.720674 \\
& 100.0 & & 12.2940835 & 12.294083 \\
1.0 & 1.0 & & 1.08727815 & 1.087278 \\
2.0 & 1.0 & & 1.14233928 & 1.142339 \\
3.0 & 1.0 & & 1.18529031 & 1.185290 \\
\hline
\end{tabular}

The above PDE Eqns. (1)-(4) and boundary conditions can be converted into nonlinear coupled ODE by using the following similarity transformations [30, 33].

$$
\begin{aligned}
& \zeta=\left(\frac{(n+1) U_{0}}{2 v}\right)^{0.5}(x+c)^{0.5(n-1)} y, u=U_{0}(x+c)^{n} F^{\prime}(\zeta), \\
& v=-\left(\frac{v(n+1) U_{0}}{2}\right)^{0.5}(x+c)^{0.5(n-1)}\left(\zeta \frac{n-1}{n+1} F^{\prime}(\zeta)+F(\zeta)\right), \\
& \psi=\left(\frac{2 v U_{0}}{(n+1)}\right)^{0.5}(x+c)^{0.5(n+1)} F(\zeta), \Theta(\zeta)=\frac{T-T_{\infty}}{T_{w}-T_{\infty}}, \\
& \Phi(\zeta)=\frac{C-C_{\infty}}{C_{w}-C_{\infty}} .
\end{aligned}
$$

With the help of Eqns. (5)-(6), Eqns. (2)-(4) are converted as follows:

$$
\begin{aligned}
& \frac{1}{\left(1-\phi_{1}\right)^{2.5}\left(1-\phi_{2}\right)^{2.5}} F^{\prime \prime \prime}-\frac{2 M}{n+1}\left(F^{\prime}-A\right) \\
& +\frac{\rho_{h n f}}{\rho_{f}}\left(F F^{\prime \prime}-\frac{2 n}{n+1}\left(\left(F^{\prime}\right)^{2}-A^{2}\right)+\frac{2}{n+1} \frac{\left(\rho \beta_{T}\right)_{h n f}}{\left(\rho \beta_{T}\right)_{f}} G r \Theta\right)=0 \\
& \frac{1}{\operatorname{Pr}} \frac{k_{h n f}}{k_{f}} \Theta^{\prime \prime}+\frac{\left(\rho C_{p}\right)_{\text {mnf }}}{\left(\rho C_{p}\right)_{f}}\left(F \Theta^{\prime}+\frac{n-1}{n+1} F^{\prime} \Theta\right)+\frac{E c}{\left(1-\phi_{1}\right)^{2.5}\left(1-\phi_{2}\right)^{2.5}} F^{\prime \prime 2} \\
& +\frac{2 M E c}{n+1}\left(F^{\prime}-A\right)^{2}=0,
\end{aligned}
$$

with the boundary conditions,

$$
\begin{aligned}
& \mathrm{F}(\zeta)=\lambda\left(\frac{1-n}{1+n}\right) F^{\prime}(\zeta), F^{\prime}(\zeta)=1+\tau_{1} F^{\prime \prime}(\zeta), \\
& \Theta(\zeta)=1+\tau_{2} \Theta^{\prime}(\zeta) \text { at } \zeta=\lambda \\
& F^{\prime}(\zeta)=A, \Theta(\zeta)=0, \text { as } \zeta \rightarrow \infty
\end{aligned}
$$

Eqns. (7)-(9) are nonlinear and coupled having the domain $[\lambda, \infty)$. In order to make the computations easier, it should be transformed as $[\lambda, \infty)$. So, we establish a new function [32].

$$
\begin{aligned}
& F(\zeta)=f(\zeta-\lambda)=f(\eta) \\
& G(\zeta)=g(\zeta-\lambda)=g(\eta), \\
& \Theta(\zeta)=\theta(\zeta-\lambda)=\theta(\eta), \\
& \Phi(\zeta)=\phi(\zeta-\lambda)=\phi(\eta)
\end{aligned}
$$

So, Eqns. (7)-(9) becomes:

$$
\begin{gathered}
\frac{1}{\left(1-\phi_{1}\right)^{2.5}\left(1-\phi_{2}\right)^{2.5}} f^{\prime \prime \prime}-\frac{2 M}{n+1}\left(f^{\prime}-A\right) \\
+\frac{\rho_{h n f}}{\rho_{f}}\left(f f^{\prime \prime}-\frac{2 n}{n+1}\left(\left(f^{\prime}\right)^{2}-A^{2}\right)+\frac{2}{n+1} \frac{\left(\rho \beta_{T}\right)_{h n f}}{\left(\rho \beta_{T}\right)_{f}} G r \theta\right)=0 \\
\frac{1}{\operatorname{Pr}} \frac{k_{h n f}}{k_{f}} \theta^{\prime \prime}+\frac{\left(\rho C_{p}\right)_{h n f}}{\left(\rho C_{p}\right)_{f}}\left(f \theta^{\prime}+\frac{n-1}{n+1} f^{\prime} \theta\right) \\
+\frac{E c}{\left(1-\phi_{1}\right)^{2.5}\left(1-\phi_{2}\right)^{2.5}} f^{\prime \prime 2}+\frac{2 M E c}{n+1}\left(f^{\prime}-A\right)^{2}=0,
\end{gathered}
$$

with the boundary conditions,

$$
\begin{aligned}
& f(0)=\lambda\left(\frac{1-n}{1+n}\right) f^{\prime}(0), f^{\prime}(0)=1+\tau_{1} f^{\prime \prime}(0), \\
& \theta(0)=1+\tau_{2} \theta^{\prime}(0), f^{\prime}(\infty)=A, \theta(\infty)=0
\end{aligned}
$$

where, $M$ is the magnetic parameter, $A$ is the stagnation parameter, $G r$ is the Local Grashof number, $E c$ is the Eckert number, $\lambda$ is the wall thickness variable, $\tau_{1}$ is the velocity slip variable and $\tau_{2}$ is the temperature jump parameter. Which are given by:

$$
M=\frac{\sigma B_{0}^{2}}{\rho_{f} U_{0}}, G r=\frac{g\left(\beta_{T}\right)_{f}(x+c)\left(T_{w}-T_{\infty}\right)}{u_{w}^{2}},
$$




$$
\begin{gathered}
A=\frac{u_{\infty}}{U_{0}}, E c=\frac{u_{w}^{2}}{\left(c_{p}\right)_{f}\left(T_{w}-T_{\infty}\right)}, \\
\lambda=J\left(\frac{(n+1) U_{0}}{2 v}\right)^{0.5}, \tau_{1}=\left(\frac{2-f_{1}}{f_{1}}\right) \xi_{1}\left(\frac{(n+1) U_{0}}{2 v}\right)^{0.5} \\
\text { and } \tau_{2}=\left(\frac{2-b}{b}\right) \xi_{2}\left(\frac{(n+1) U_{0}}{2 v}\right)^{0.5} .
\end{gathered}
$$

For the sake of engineering interest, skin friction coefficient, heat and mass transfer rates are:

$$
\begin{aligned}
C_{f} \operatorname{Re}_{x}^{1 / 2} / 2 & =\left(\frac{1+n}{2}\right)^{0.5} \frac{1}{\left(1-\phi_{1}\right)^{2.5}\left(1-\phi_{2}\right)^{2.5}} f^{\prime \prime}(0), \\
\mathrm{Nu}_{x} \operatorname{Re}_{x}^{-1 / 2} & =-\left(\frac{1+n}{2}\right)^{0.5} \frac{k_{h n f}}{k_{f}} \theta^{\prime}(0),
\end{aligned}
$$

\section{ANALYSIS OF ENTROPY EQUATION}

The entropy generation rate per unit volume is defined as:

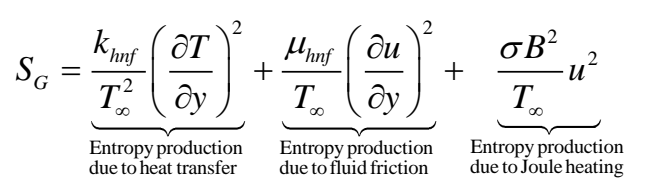

With the help of Eqns. (5)-(6), Eq. (14) is converted as follows:

$$
\begin{aligned}
N_{G}= & \underbrace{\frac{k_{h n f}}{k_{f}} \alpha_{1} \theta^{\prime 2}}_{\text {Conductive irreversibility }}+\underbrace{\frac{B r}{\left(1-\phi_{1}\right)^{2.5}\left(1-\phi_{2}\right)^{2.5}} f^{\prime \prime 2}}_{\text {Viscous irreversibility }} \\
& +\underbrace{\frac{2}{n+1} M B r f^{\prime 2}}_{\substack{\text { Joule dissipation } \\
\text { irreversibibity }}},
\end{aligned}
$$

$N_{G}\left(=\frac{2 S_{G} T_{\infty} v_{f} u_{w}(x+c)}{(n+1) k_{f} \Delta T}\right)$ the local entropy generation, $\alpha_{1}=\frac{\Delta T}{T \infty} \quad$ T, dimensionless ratio variable, $\quad B r\left(=\frac{\mu_{f} u_{w}^{2}}{k_{f} \Delta T}\right)$ Brinkman number.

The Bejan number is defined as:

$$
\begin{gathered}
B e=\frac{\text { Entropy generation due to heat transfer }}{\text { Total entropy generation }}, \\
B e=\frac{\frac{k_{h n f}}{k_{f}} \alpha_{1} \theta^{\prime 2}}{\frac{k_{h n f}}{k_{f}} \alpha_{1} \theta^{\prime 2}+\frac{B r f^{\prime 2}}{\left(1-\phi_{1}\right)^{2.5}\left(1-\phi_{2}\right)^{2.5}}+\frac{2}{n+1} M B r f^{\prime 2}},
\end{gathered}
$$

\section{NUMERICAL PROCEDURE}

$>$ The set of higher order nonlinear differential Eqns. (10)-(12) have been reduced to a first-order equations. Which are:

$$
\begin{gathered}
f_{3}{ }^{\prime}=\left(1-\phi_{1}\right)^{2.5}\left(1-\phi_{2}\right)^{2.5}\left\{\frac{2 M}{n+1}\left(f_{2}-A\right)\right. \\
\left.-\frac{\rho_{h n f}}{\rho_{f}}\left(f_{1} f_{3}-\frac{2 n}{n+1}\left(f_{2}^{2}-A^{2}\right)+\frac{2}{n+1} \frac{\left(\rho \beta_{T}\right)_{h n f}}{\left(\rho \beta_{T}\right)_{f}} G r f_{4}\right)\right\} \\
f_{5}{ }^{\prime}=\operatorname{Pr} \frac{k_{f}}{k_{h n f}}\left\{-\frac{\left(\rho C_{p}\right)_{h n f}}{\left(\rho C_{p}\right)_{f}}\left(f_{1} f_{5}+\frac{n-1}{n+1} f_{2} f_{4}\right)\right. \\
\left.-\frac{E c}{\left(1-\phi_{1}\right)^{2.5}\left(1-\phi_{2}\right)^{2.5}} f_{3}{ }^{2}-\frac{2 M E c}{n+1}\left(f_{2}-A\right)^{2}\right\}
\end{gathered}
$$

where,

$$
f=f_{1}, f^{\prime}=f_{2,} f^{\prime \prime}=f_{3}, \theta=f_{4}, \theta^{\prime}=f_{5} .
$$

with boundary conditions,

$$
\begin{aligned}
& f_{1}(0)=\lambda\left(\frac{1-n}{1+n}\right) f_{2}(0), f_{2}(0)=1+\tau_{1} f_{3}(0), f_{2}\left(\eta_{\infty}\right)=A, \\
& f_{4}(0)=1+\tau_{2} f_{5}(0), f_{4}\left(\eta_{\infty}\right)=0 .
\end{aligned}
$$

An essential aspect of the shooting technique is the selection of a reasonably limited rating of $\eta_{\infty}$.

$>$ The error tolerance is $10^{-8}$ and $h=0.001$ is the step size of the fourth order Runge-Kutta with shooting method algorithm (see Figure 2).

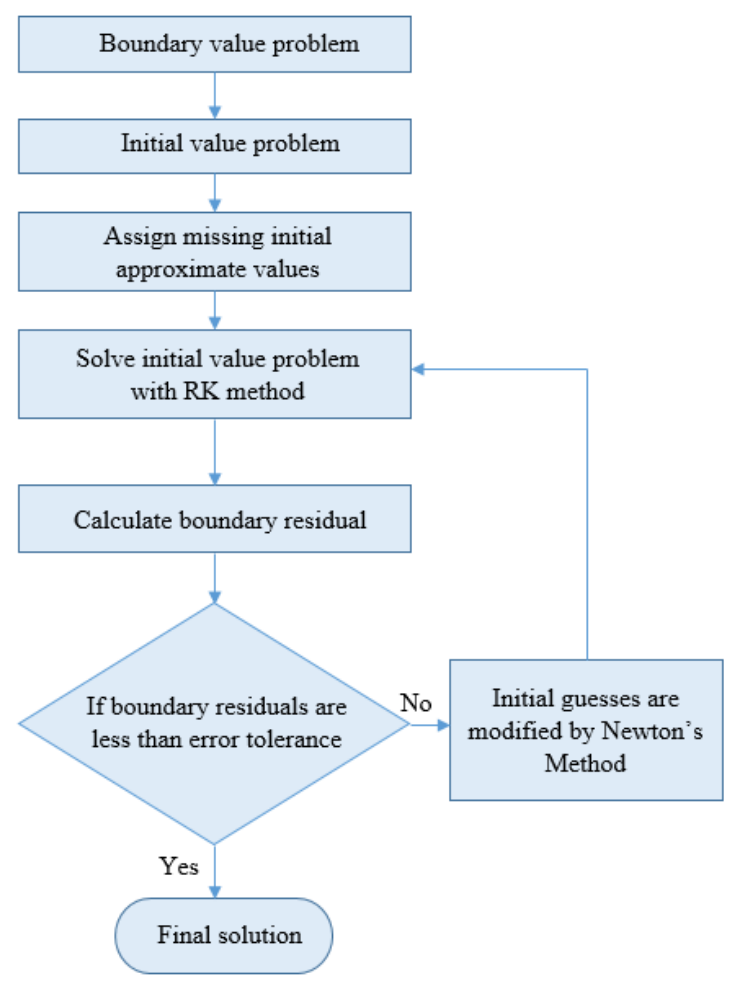

Figure 2. Schematic diagram of shooting scheme 


\section{RESULTS AND DISCUSSION}

We conferred the impression of various flow parameters in this section, such as stagnation parameter $(A)$, Magnetic parameter $(M)$, Local Grashof number $(G r)$, volume fraction of silver nanoparticle $\left(\phi_{1}\right)$, volume fraction of Graphene nanoparticle $\left(\phi_{2}\right)$, Eckert number $(E c)$, Brinkman number $(\mathrm{Br})$, Temperature difference parameter $\left(\alpha_{1}\right)$ on velocity $\left(f^{\prime}(\eta)\right)$, temperature $(\theta(\eta))$, local entropy generation $\left(N_{G}\right)$, Bejan number $(B e)$, surface drag force $\left(\operatorname{Re}_{\mathrm{x}}{ }^{1 / 2} \mathrm{C}_{\mathrm{f}} / 2\right)$ and rate of heat transfer $\left(\mathrm{Nu}_{\mathrm{x}} \mathrm{Re}_{\mathrm{x}}{ }^{-1 / 2}\right)$ are inspected through graphical interpretations for the silver-Graphene hybrid nanoparticles with the combination of Ethylene Glycol-water mixture having the ratios $0: 100 \%, 20: 80 \%$ and $40: 60 \%$ respectively.

In this study, we considered the various parameters as $\phi_{1}=0.01, \phi_{2}=0.01, A=0.4, G r=0.4, E c=0.5, \lambda=0.2, \tau_{1}=1, \tau_{2}=1$, $n=0.5, \alpha_{1}=1$, and $B r=0.2$. These values have been not different all through the study apart from the values shown in figure.

\subsection{Influences of various parameters on velocity profile}

For the different combinations of EG-water mixture, the sway of $A$ on dimensionless velocity profiles as shown in Figure 3 . As identified from this figure, with growing $A$ values, the velocity rises.

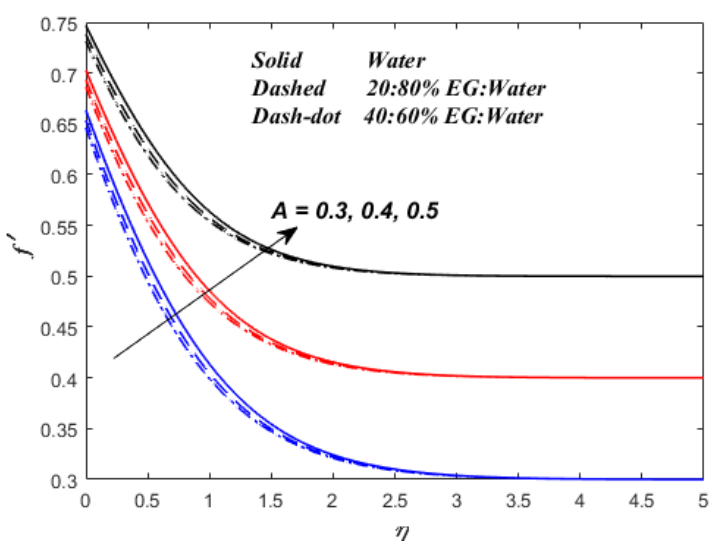

Figure 3. Influence of $A$ on $f^{\prime}(\eta)$

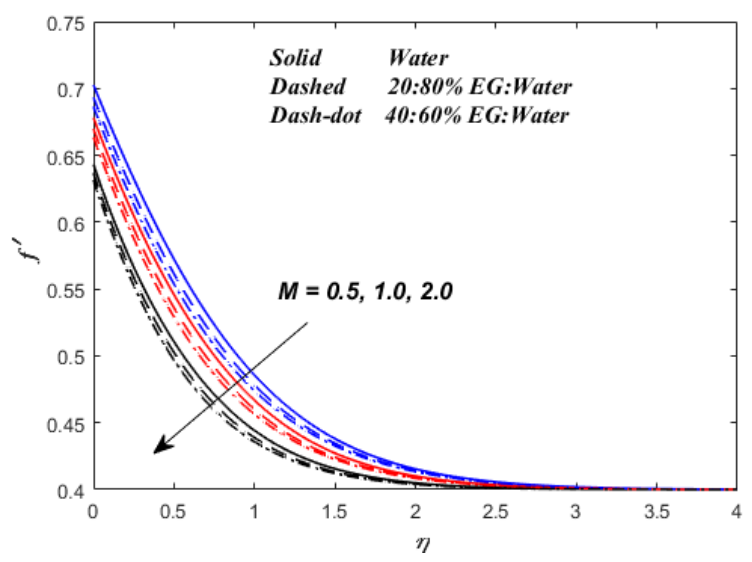

Figure 4. Influence of $M$ on $f^{\prime}(\eta)$

Figure 4 demonstrates the impact of $M$ for different combinations of the EG-water mixture on the velocity profile. It is realized that the velocity of the fluid declines with large values of the $M$. These findings are consistent with the reality that the resistive force, which plays a vital part in deceleration and directional fluid flow, is the applied magnetic field. The dimensionless velocity outlines for different values of $\mathrm{Gr}$ are shown in Figure 5. The velocity increases for large quantities of $\mathrm{Gr}$ while a diminishing in the parameter diminishes the velocity of the fluid because of cooling.

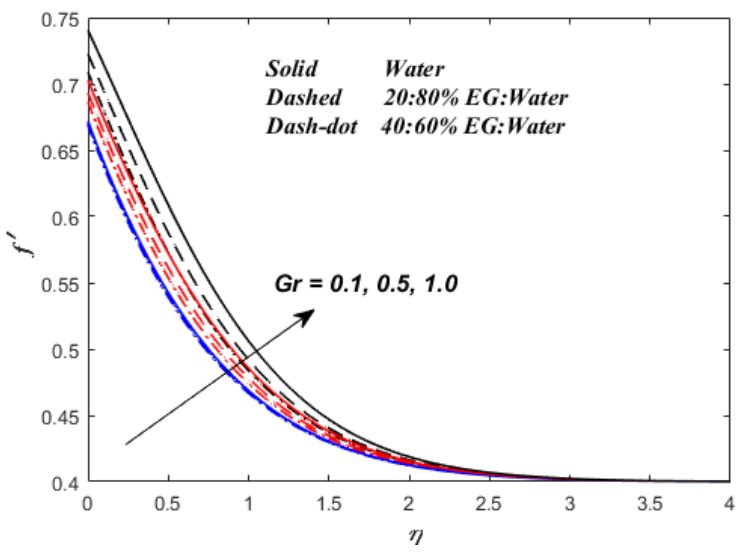

Figure 5. Influence of $G r$ on $f^{\prime}(\eta)$

\subsection{Impacts of innumerable parameters on temperature outlines}

Figures 6-10 showed the impact on the temperature profile for the $A, M, \phi_{1}, \phi_{2}$ and $E c$. From Figure 6, it is clearly shown that temperature has increasing behavior in case of magnetic parameter. More Lorentz force provides additional resistance to the movement of energy cells. Due to this, more heat is generated inside the system, and as a result, the temperature rises. In the view of Figure 7, it is witnessed that the nanofluid temperature decreases for increasing values of stagnation parameter.

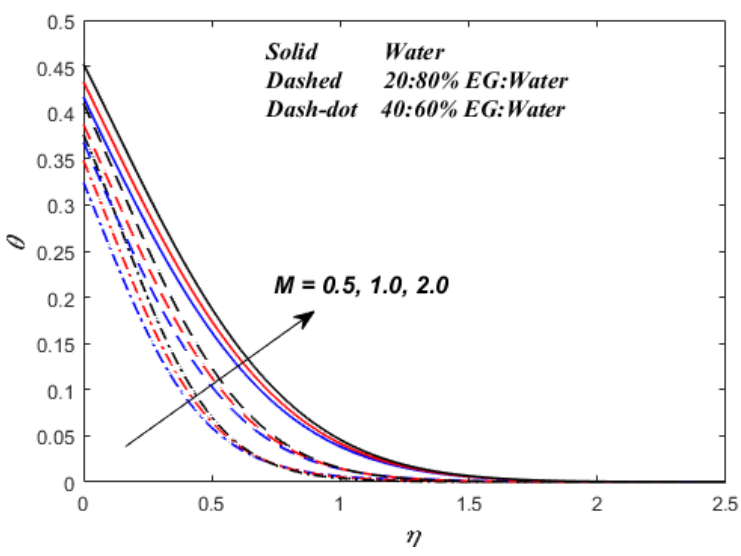

Figure 6. Influence of $M$ on $\theta(\eta)$

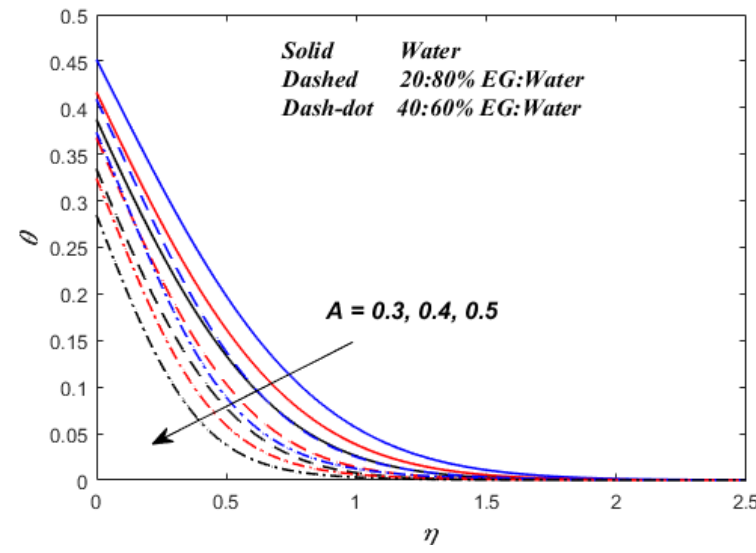

Figure 7. Influence of $A$ on $\theta(\eta)$ 
From Figures 8-10, a similar tendency of temperature enrichment was observed with increasing values of $\phi_{1}, \phi_{2}$ and $E c$. From a physical perspective, the thermal conductivity increases with $\phi_{1}$ and $\phi_{2}$. With higher thermal conductivity the liquid temperature increases.

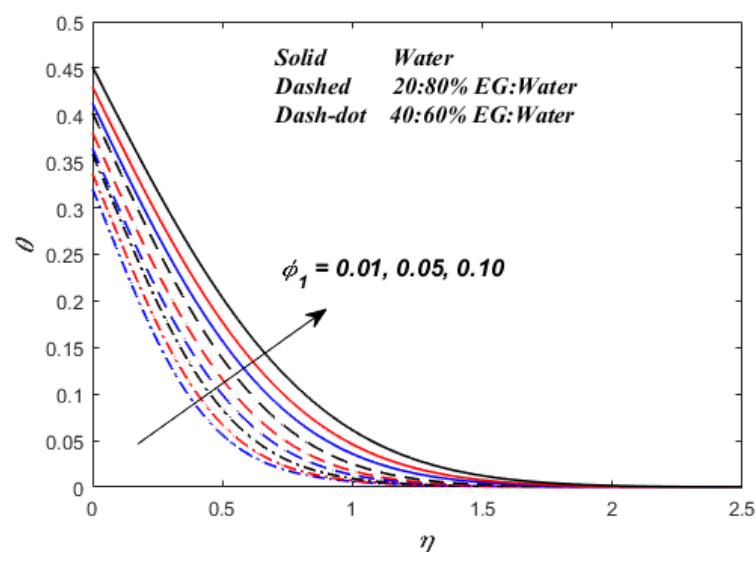

Figure 8. Influence of $\phi_{1}$ on $\theta(\eta)$

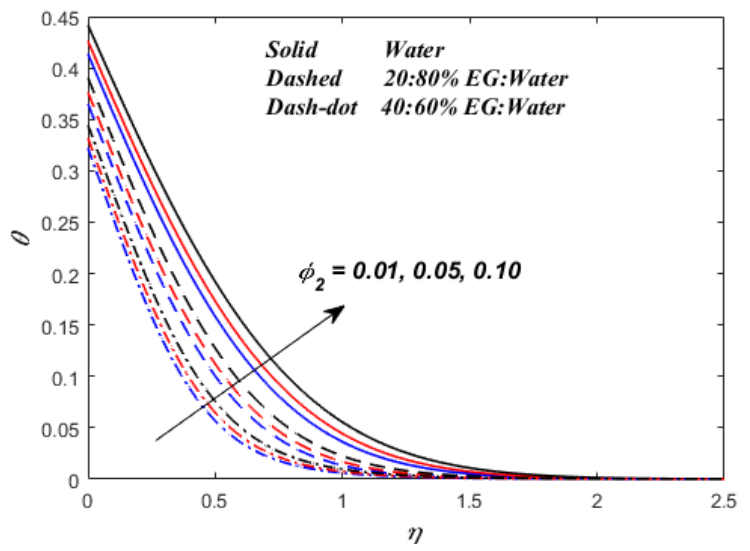

Figure 9. Influence of $\phi_{2}$ on $\theta(\eta)$

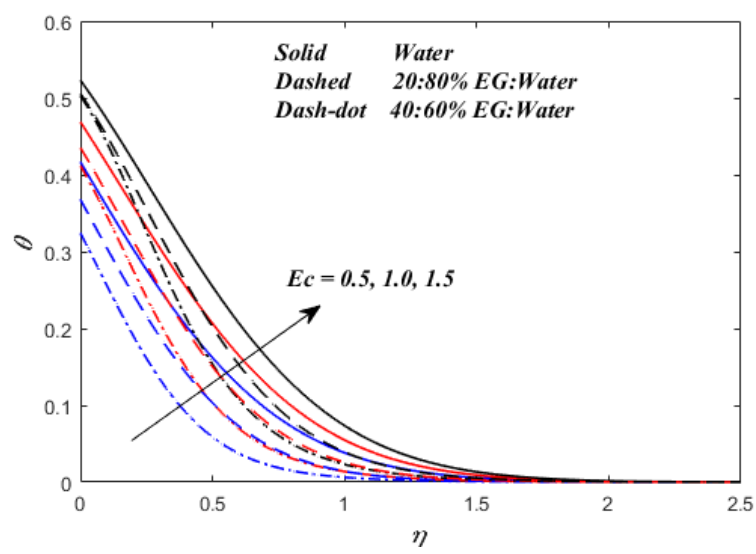

Figure 10. Influence of $E c$ on $\theta(\eta)$

\subsection{Inspirations of different parameters on entropy generation}

The computed values of the local entropy generation distribution for various values of $A, \phi_{1}, \phi_{2}, M, E c, B r$ and $\alpha_{1}$ are portrayed in Figures 11-17 respectively. Figure 11 discoveries that $M$ has increasing results on entropy generation. Physically, the enrichment of Lorentz force with rise in magnetic parameter results in more friction which causes the entropy generation rate to supplement. It is vivacious from Figure 12 that the entropy generation rate intensifications when the $E c$ intensifications. Physically heat is a form of disorganized energy. So, more heat transfer to the system is generated owed to entropy. That's why kinetic energy of liquid particles rehabilitated low grade energy and subsequently entropy generation enhances. We perceived from Figure 13 that entropy generation rate is growing for higher values of $\mathrm{Br}$. It stems from the fact that, for higher $\mathrm{Br}$ the conduction rate is leisurelier formed by dissipation, that's why boosts the entropy generation rate. Figures 14-17 it is analyzed that entropy generation rate is increased by enhancing $\phi_{1}, \phi_{2}$ and $\alpha_{1}$ where as reverse trend is observed in $A$.

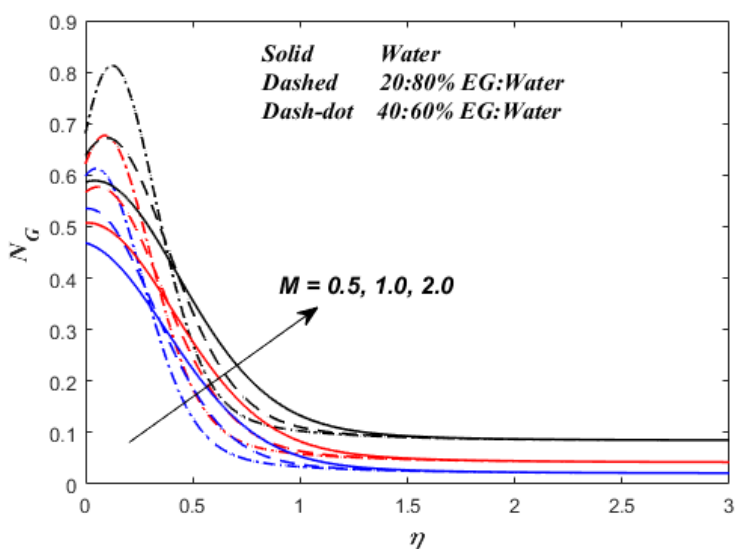

Figure 11. Influence of $M$ on $N_{G}$

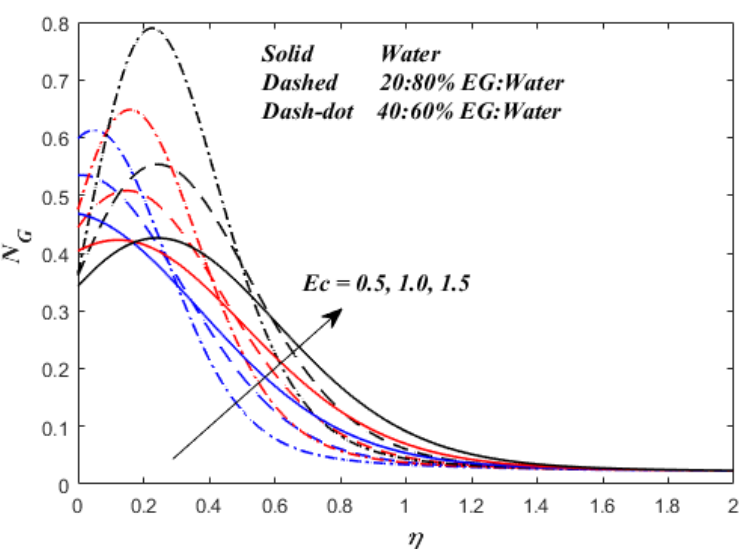

Figure 12. Influence of $E c$ on $N_{G}$

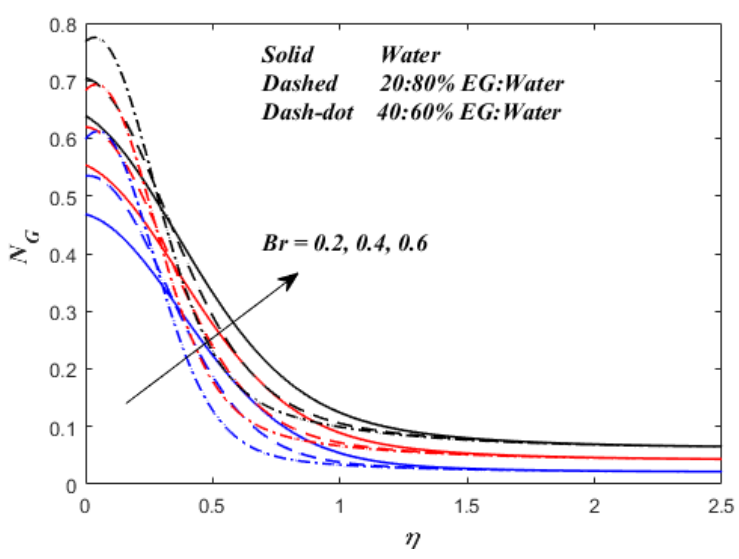

Figure 13. Influence of $\mathrm{Br}$ on $N_{G}$ 


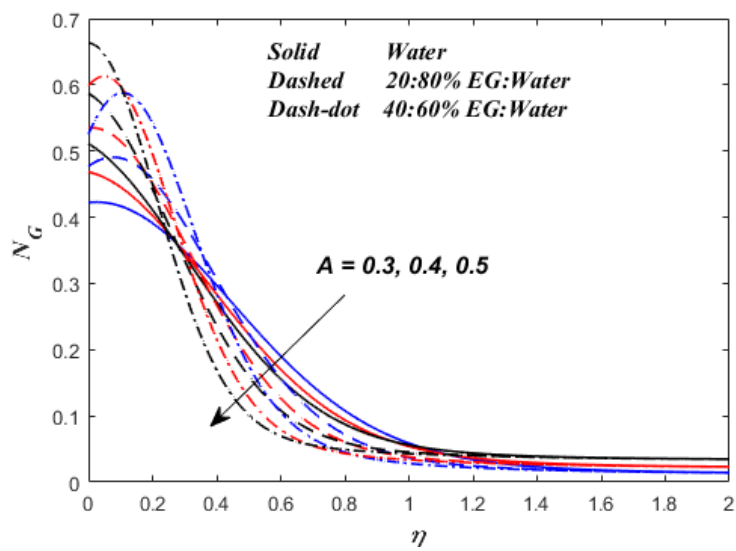

Figure 14. Influence of $A$ on $N_{G}$

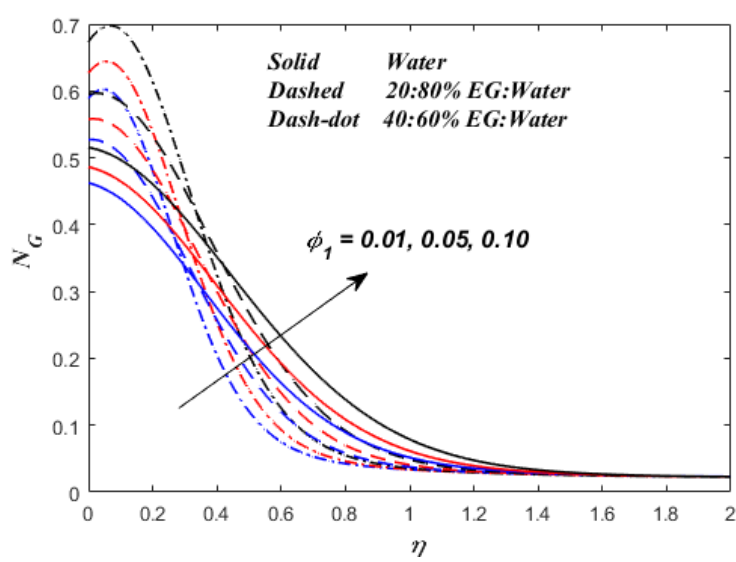

Figure 15. Influence of $\phi_{1}$ on $N_{G}$

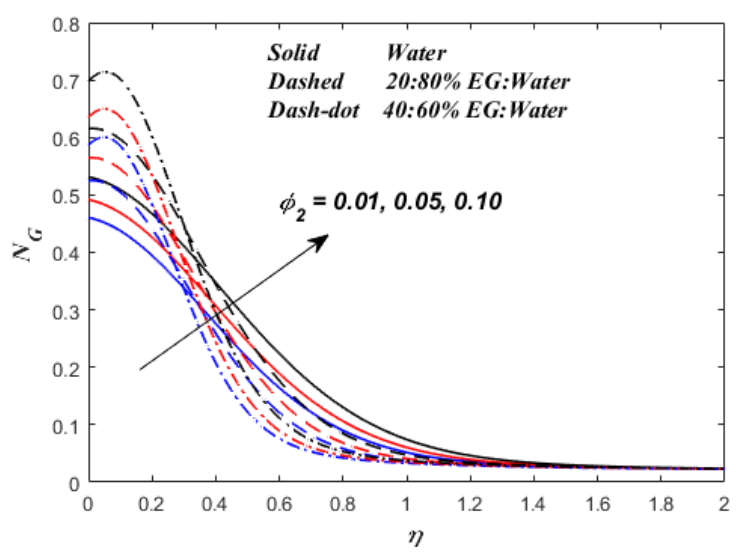

Figure 16. Influence of $\phi_{2}$ on $N_{G}$

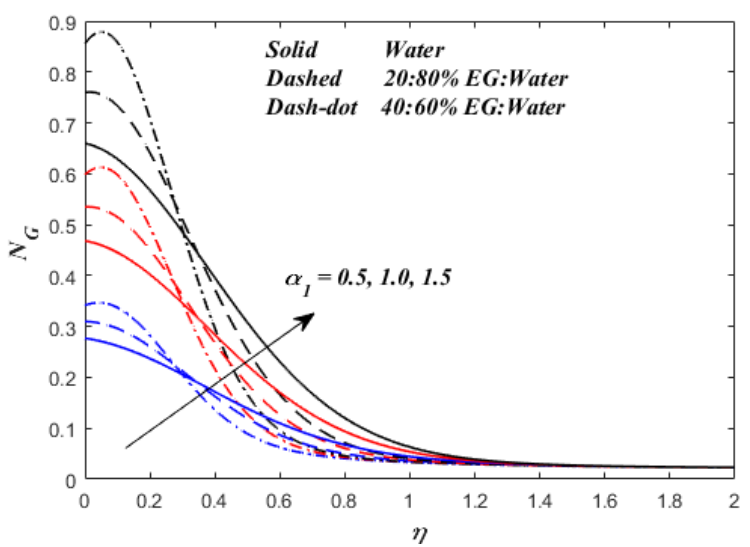

Figure 17. Influence of $\alpha_{1}$ on $N_{G}$
5.4 Effects of various parameters on Bejan number

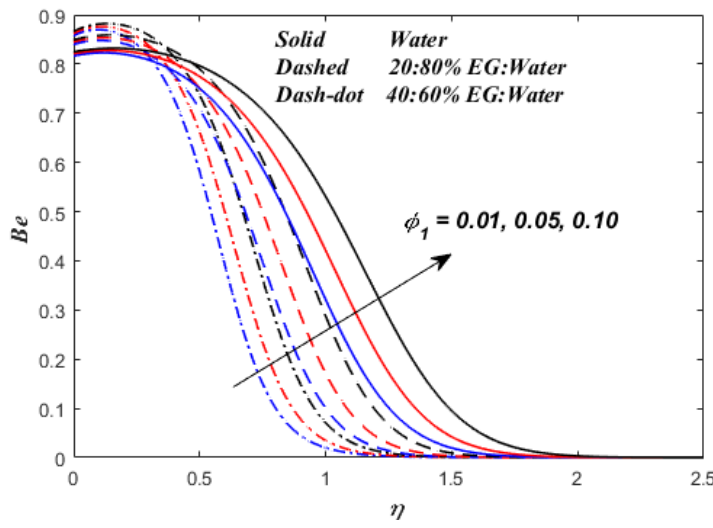

Figure 18. Influence of $\phi_{1}$ on $B e$

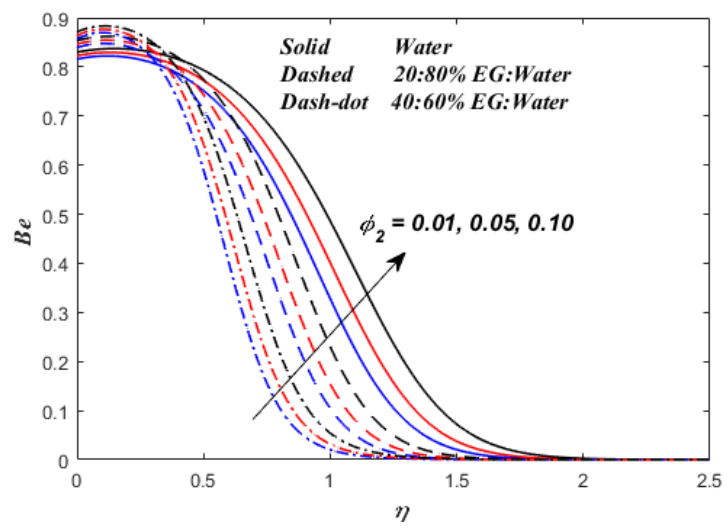

Figure 19. Influence of $\phi_{2}$ on $B e$

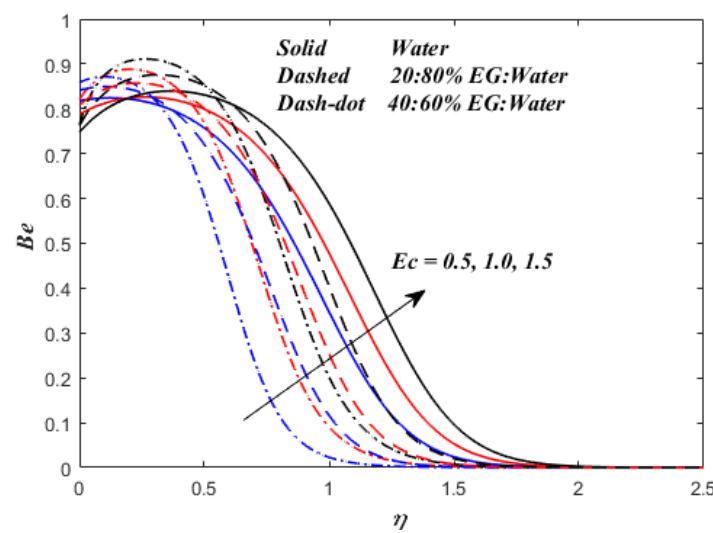

Figure 20. Influence of $E c$ on $B e$

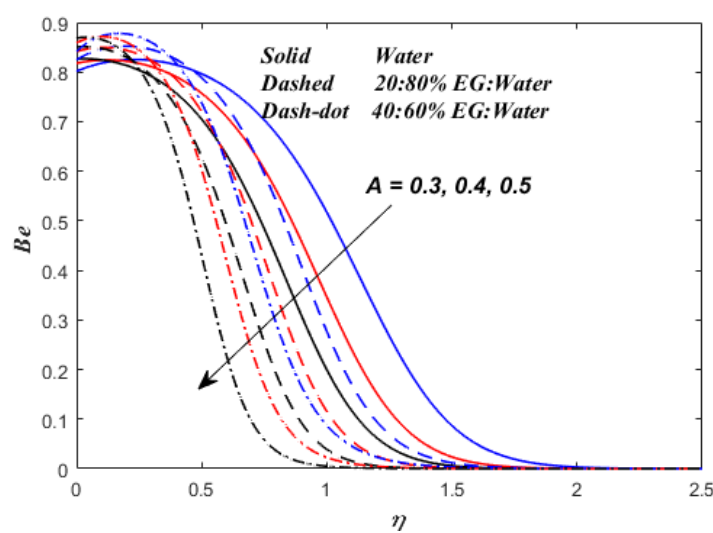

Figure 21. Influence of $A$ on $B e$ 


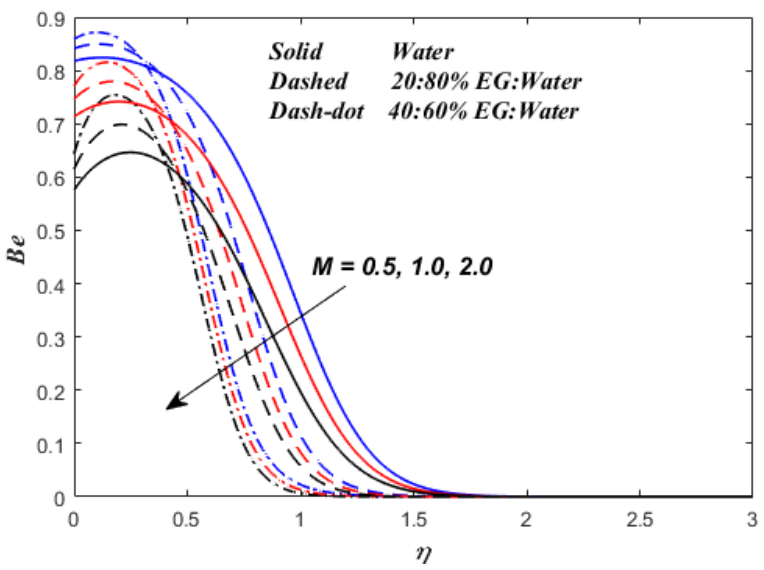

Figure 22. Influence of $M$ on $B e$

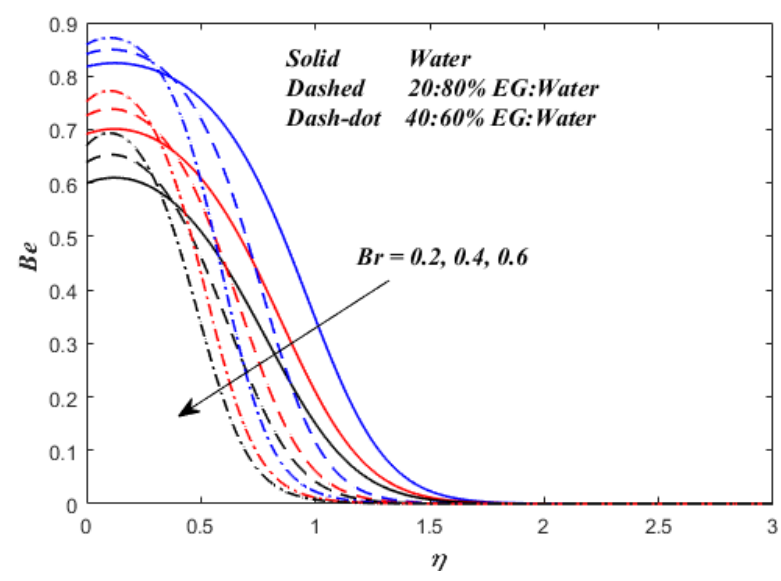

Figure 23. Influence of $\mathrm{Br}$ on $\mathrm{Be}$

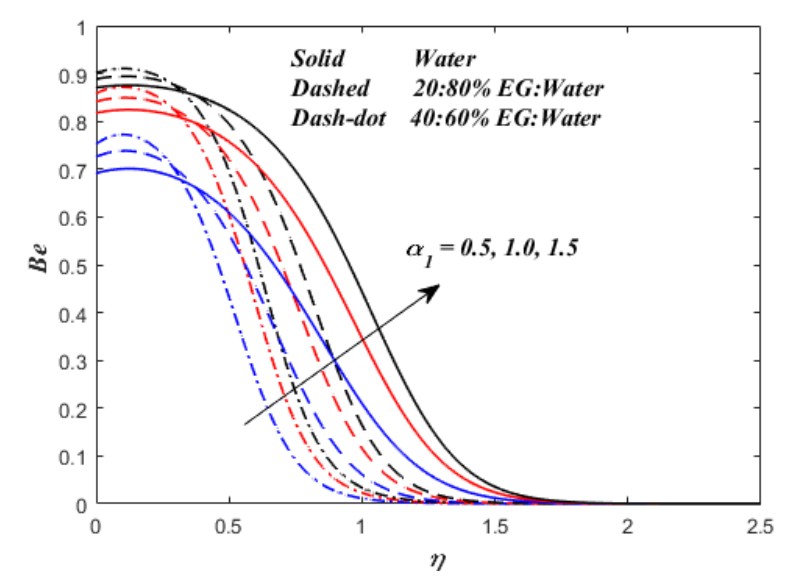

Figure 24. Influence of $\alpha_{1}$ on $B e$

Figures 18-24 elucidate the performance of Bejan number for the various values of $\phi_{1}, \phi_{2}, A, E c, M, B r$ and $\alpha_{1}$ respectively. The Bejan number increases for larger values of volume fraction of $\phi_{1}, \phi_{2}, E c$, and $\alpha_{1}$, whereas the contrary propensity is perceived for $A, M$ and $B r$. The large $B r$ increases the entropy rate physically and thus decreases the Bejan.

\subsection{Effects of various parameters on skin friction and rate of heat transfer}

The impact of the increase in the $\phi_{1}$ and $\phi_{2}$ on the surface drag force has been shown in Figure 25. The higher values of of nanoparticles declines the surface drag force. In Figures 26-
28 , the behavior of the rate of heat transfer in terms of changes in $\phi_{1}, \phi_{2}$ and $E c$ are indicated. From Figure 26 the heat transfer rate enhances with both $\phi_{1}$ and $\phi_{2}$ increases. In Figure 27, the value of $\phi_{2}$ is fixed and $\phi_{1}$ and $E c$ are vary on the rate of heat transfer. The value of $\phi_{1}$ is fixed and $\phi_{2}$ and $E c$ are varying on the rate of heat transfer are shown in Figure 28. Rate of heat transfer enhances with large values of $\phi_{1}, \phi_{2}$ and smaller values of $E c$. Finally, rate of heat transfer is more for $\phi_{2}$ than $\phi_{1}$.

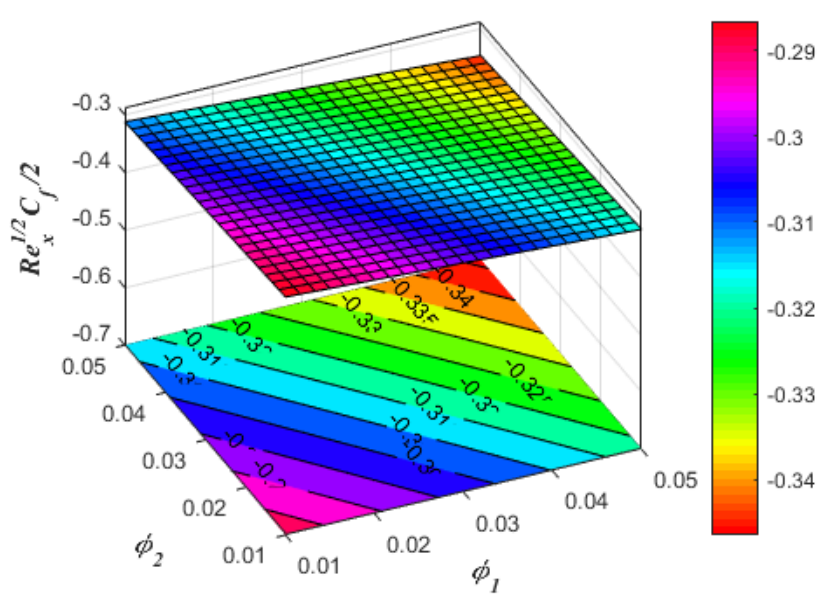

Figure 25. Influence of $\phi_{2}$ and $\phi_{1}$ on $\operatorname{Re}_{\mathrm{x}}{ }^{1 / 2} \mathrm{C}_{\mathrm{f}} / 2$

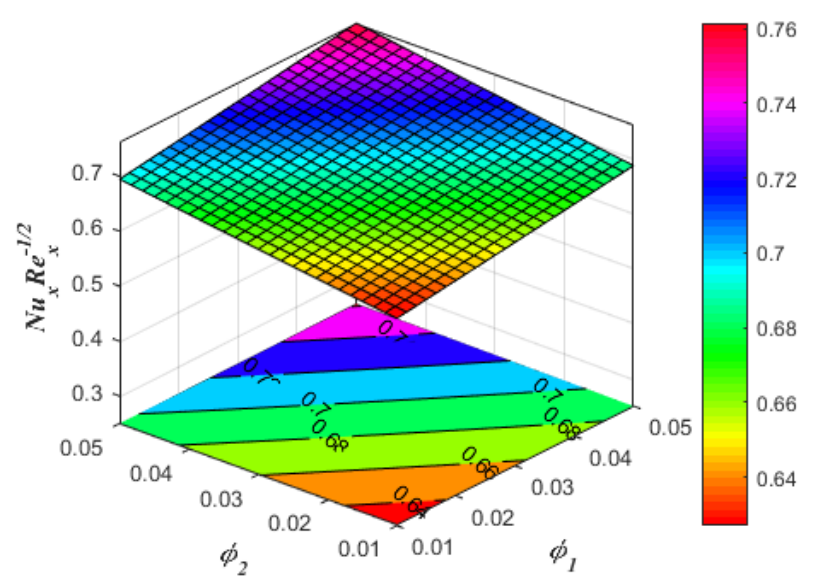

Figure 26. Influence of $\phi_{2}$ and $\phi_{1}$ on $\mathrm{Nu}_{\mathrm{x}} \mathrm{Re}_{\mathrm{x}}{ }^{-1 / 2}$

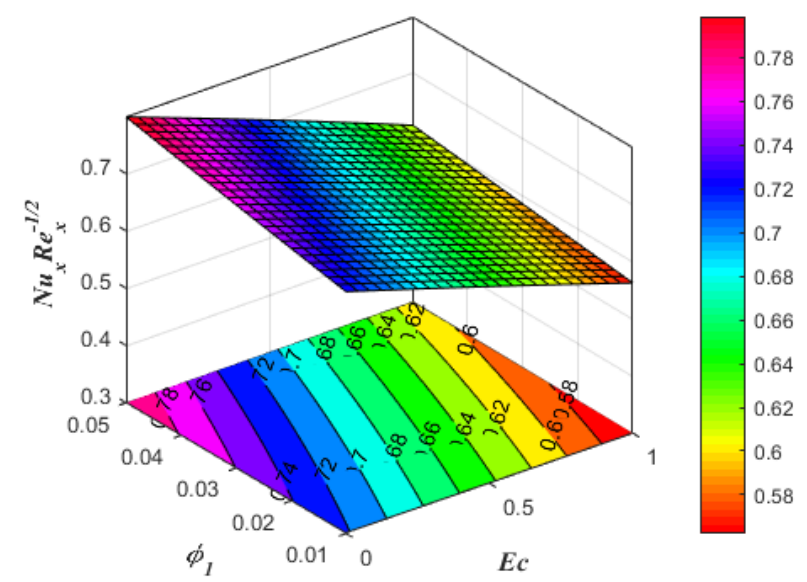

Figure 27. Influence of $\phi_{1}$ and $E c$ on $\mathrm{Nu}_{\mathrm{x}} \mathrm{Re}_{\mathrm{x}}{ }^{-1 / 2}$ 


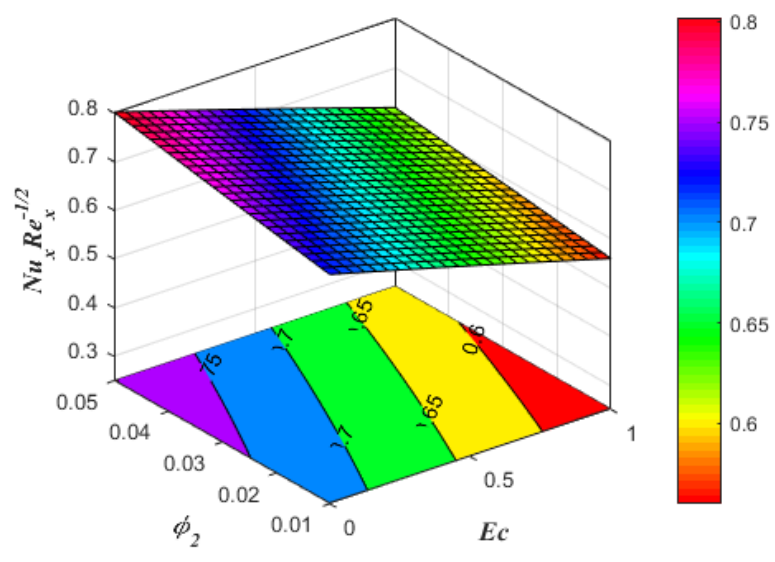

Figure 28. Influence of $\phi_{2}$ and $E c$ on $\mathrm{Nu}_{\mathrm{x}} \mathrm{Re}_{\mathrm{x}}{ }^{-1 / 2}$

\section{CONCLUSIONS}

This article carried out the numerical study on MHD silvergraphene/water-ethylene glycol hybrid nanofluids over an upper horizontal surface of a paraboloid of revolution. RungeKutta incorporate with the shooting method has been employed to solve the non-dimensional flow equations. Thermal conductivity of water is higher than pure glycol. Ethylene glycol has considerable potential for automotive and residential heating applications, particularly in the world's cold areas. Various percentages of water mixed with ethylene glycol or propylene glycol are used as heat transfer fluids owing to winter climatic circumstances in Alaska, Canada, Northern Europe and Russia. Because of thermal conductivity of water is higher than pure glycol. The combination of the two liquids has a lower freezing point than water and higher thermal conductivity than pure glycol. Even if the operating temperature reaches $-40^{\circ} \mathrm{C}$, these liquids do not freeze. Ethylene glycol mixtures have better thermo physical characteristics than propylene glycol mixtures at temperatures as low. If the concentration of water is high in ethylene glycol, the rate of heat transfer also increases. With lower $E c$ values and higher $\phi_{1}$ and $\phi_{2}$ values, the heat transfer rate is higher. Entropy generation rate $\left(N_{G}\right)$ and Bejan number $(B e)$ are enhanced for higher values of $\alpha_{1}, \phi_{1}$ and $\phi_{2}$.

\section{REFERENCES}

[1] Choi, S.U.S., Eastman, J.A. (1995). Enhancing thermal conductivity of fluids with nanoparticles. ASME International Mechanical Congress and Exposition, SanFrancisco, USA, 99-105.

[2] Turkyilmazoglu, M. (2016). Flow of nanofluid plane wall jet and heat transfer. European Journal of Mechanics B/Fluids, 59: https://doi.org/10.1016/j.euromechflu.2016.04.007

[3] Akbar, N.S., Tripathi, D., Khan, Z.H. (2018). Numerical investigation of Cattanneo-Christov heat flux in CNT suspended nanofluid flow over a stretching porous surface with suction and injection. Discrete and Continuous Dynamical Systems-Series S, 11(4): 583594. https://doi.org/10.3934/dcdss.2018033

[4] Ellahi, R., Zeeshan, A., Shehzad, N., Alamri, S.Z. (2018). Structural impact of kerosene- $\mathrm{Al}_{2} \mathrm{O}_{3}$ nanoliquid on MHD
Poiseuille flow with variable thermal conductivity: Application of cooling process. Journal of Molecular Liquids, 264: 607-615 https://doi.org/10.1016/j.molliq.2018.05.103

[5] Reddy, S.R.R., Bala Anki Reddy, P. (2018). Biomathematical analysis for the stagnation point flow over a non-linear stretching surface with the second order velocity slip and titanium alloy nanoparticle. Frontiers in Heat and Mass Transfer, 10(13): 1-11. https://doi.org/10.5098/hmt.10.13

[6] Kandasamy, R., bt Adnan, N.A., Abbood, J.A.A., Kamarulzaki, M., Saifullah, M. (2019). Electric field strength on water based aluminum alloys nanofluids flow up a non-linear inclined sheet. Engineering Science and Technology, 22: 229-236. https://doi.org/10.1016/j.jestch.2018.10.004

[7] Hayat, T., Imtiaz, M., Alsaedi, A. (2016). Melting heat transfer in the MHD flow of $\mathrm{Cu}$-water nanofluid with viscous dissipation and Joule heating. Advanced Powder Technology, 27(4): 1301-1308. https://doi.org/10.1016/j.apt.2016.04.024

[8] Sheikholeslami, M., Gorji-Bandpy, M., Vajravelu, K. (2015). Lattice Boltzmann simulation of magnetohydrodynamic natural convection heat transfer of $\mathrm{Al}_{2} \mathrm{O}_{3}$-water nanofluid in a horizontal cylindrical enclosure with an inner triangular cylinder. International Journal of Heat and Mass Transfer, 80: 16-25. https://doi.org/10.1016/j.ijheatmasstransfer.2014.08.090

[9] Nayak, R.K., Bhattacharyya, S., Pop, I. (2015). Numerical study on mixed convection and entropy generation of $\mathrm{Cu}$-water nanofluid in a differentially heated skewed enclosure. International Journal of Heat and Mass Transfer, 85: 620-634. https://doi.org/10.1016/j.ijheatmasstransfer.2015.01.116

[10] Ma, Y., Mohebbi, R., Rashidi, M.M., Yang, Z. (2019). MHD convective heat transfer of $\mathrm{Ag}-\mathrm{MgO} /$ water hybrid nanofluid in a channel with active heaters and coolers. International Journal of Heat and Mass Transfer, 137: 714-726.

https://doi.org/10.1016/j.ijheatmasstransfer.2019.03.169

[11] Iqbal, Z., Akbar, N.S., Azhar, E., Maraj, E.N. (2018). Performance of hybrid nanofluid $(\mathrm{Cu}-\mathrm{CuO} /$ water) on MHD rotating transport in oscillating vertical channel inspired by Hall current and thermal radiation. Alexandria Engineering Journal, 57(3): 1943-1954. https://doi.org/10.1016/j.aej.2017.03.047

[12] Sajjadi, H., Amiri Delouei, A., Izadi, M., Mohebbi, R. (2019). Investigation of MHD natural convection in a porous media by double MRT lattice Boltzmann method utilizing MWCNT- $\mathrm{Fe}_{3} \mathrm{O}_{4} /$ water hybrid nanofluid. International Journal of Heat and Mass Transfer, 132: 1087-1104.

https://doi.org/10.1016/j.ijheatmasstransfer.2018.12.060

[13] Dogonchi, A.S., Ganji, D.D. (2016). Investigation of MHD nano fluid flow and heat transfer in a stretching / shrinking convergent / divergent channel considering thermal radiation. Journal of Molecular Liquids, 220: 592-603. https://doi.org/10.1016/j.molliq.2016.05.022

[14] Izadi, M., Mohebbi, R., Karimi, D., Sheremet, M.A. (2018). Numerical simulation of natural convection heat transfer inside a $\perp$ shaped cavity filled by a MWCNT$\mathrm{Fe}_{3} \mathrm{O}_{4} /$ water hybrid nano fluids using LBM. Chemical Engineering \& Processing: Process Intensification, 125: 56-66. https://doi.org/10.1016/j.cep.2018.01.004 
[15] Ghadikolaei, S.S., Gholinia, M., Hoseini, M.E., Ganji, D.D. (2019). Natural convection MHD flow due to $\mathrm{MoS}_{2}$ - Ag nanoparticles suspended in $\mathrm{C}_{2} \mathrm{H}_{6} \mathrm{O}_{2}-\mathrm{H}_{2} \mathrm{O}$ hybrid base fluid with thermal radiation. Journal of the Taiwan Institute of Chemical Engineers, 97: 12-23. https://doi.org/10.1016/j.jtice.2019.01.028

[16] Nademi, M., Dinarvand, S., Pop, I. (2018). Dual solutions for mixed convective stagnation-point flow of an aqueous silica - alumina hybrid nano fluid. Chinese Journal of Physics, 56(5): 2465-2478. https://doi.org/10.1016/j.cjph.2018.06.013

[17] Shaiq, S., Maraj, E.N., Iqbal, Z. (2019). Remarkable role of $\mathrm{C}_{3} \mathrm{H}_{8} \mathrm{O}_{2}$ on transportation of $\mathrm{MoS}_{2} \mathrm{SiO}_{2}$ hybrid nanoparticles influenced by thermal deposition and internal heat generation. Journal of Physical and Chemistry of Solids, 126: 294-303. https://doi.org/10.1016/j.jpcs.2018.11.028

[18] Saba, F., Ahmed, N., Khan, U., Mohyud-din S.T. (2019). A novel coupling of $\left(\mathrm{CNT}-\mathrm{Fe}_{3} \mathrm{O}_{4} / \mathrm{H}_{2} \mathrm{O}\right)$ hybrid nanofluid for improvements in heat transfer for flow in an asymmetric channel with dilating / squeezing walls. International Journal of Heat and Mass Transfer, 136: 186-195. https://doi.org/10.1016/j.ijheatmasstransfer.2019.02.097

[19] Usman, M., Hamid, M., Zubair, T., Haq, R.U., Wang, W. (2018). $\mathrm{Cu}-\mathrm{Al}_{2} \mathrm{O}_{3} /$ Water hybrid nanofluid through a permeable surface in the presence of nonlinear radiation and variable thermal conductivity via LSM. International Journal of Heat and Mass Transfer, 126: 1347-1356. https://doi.org/10.1016/j.ijheatmasstransfer.2018.06.005

[20] Iqbal, Z., Maraj, E.N., Azhar, E., Mehmood, Z. (2017). A novel development of hybrid $\left(\mathrm{MoS}_{2}-\mathrm{SiO}_{2} / \mathrm{H}_{2} \mathrm{O}\right)$ nanofluidic curvilinear transport and consequences for effectiveness of shape factors. Journal of the Taiwan Institute of Chemical Engineers, 81: 150-158. https://doi.org/10.1016/j.jtice.2017.09.037

[21] Yarmand, H., Gharehkhani, S., Ahmadi, G., Shirazi, S.F.S., Baradaran, S., Montazer, E., Zubir, M.N.M., Alehashem, M.S., Kazi, S.N., Dahari, M. (2015). Graphene nanoplatelets - silver hybrid nanofluids for enhanced heat transfer. Energy Conversion and Management, 100: 419-428. https://doi.org/10.1016/j.enconman.2015.05.023

[22] Bahiraei, M., Heshmatian, S. (2017). Efficacy of a novel liquid block working with a nanofluid containing graphene nanoplatelets decorated with silver nanoparticles compared with conventional CPU coolers. Applied Thermal Engineering, 127: 1233-1245. https://doi.org/10.1016/j.applthermaleng.2017.08.136

[23] Cabaleiro, D., Colla, L., Agresti, F., Lugo, L., Fedele, L. (2015). Transport properties and heat transfer coefficients of $\mathrm{ZnO}$ /(ethylene glycol + water) nanofluids. International Journal of Heat and Mass Transfer, 89: 433443.

https://doi.org/10.1016/j.ijheatmasstransfer.2015.05.067

[24] Öğüt, E.B., Kahveci, K. (2016). Mixed convection characteristics of ethylene glycol and water mixture based $\mathrm{Al}_{2} \mathrm{O}_{3}$ nanofluids. Proceedings of the $2^{\text {nd }}$ World Congress on Mechanical, Chemical, and Material Engineering, pp. https://doi.org/10.11159/htff16.116
[25] Heris, S.Z., Shokrgozar, M., Poorpharhang, S., Shanbedi, M., Noie S.H. (2014). Experimental study of heat transfer of a car radiator with $\mathrm{CuO} /$ ethylene glycol-water as a coolant. Journal of Dispersion Science and Technology, 35: 677-684. https://doi.org/10.1080/01932691.2013.805301

[26] Hagos, F.Y., Abdul Hamid, K., Mamat, R., Nabil, M.F., Azmi, W.H. (2017). An experimental study on the thermal conductivity and dynamic viscosity of $\mathrm{TiO}_{2}-$ $\mathrm{SiO}_{2}$ nanofluids in water: Ethylene glycol mixture. International Communications in Heat and Mass Transfer, 86: 181-189. https://doi.org/10.1016/j.icheatmasstransfer.2017.05.02 4

[27] Sundar, L.S., Singh, M.K., Sousa, A.C.M. (2013). Thermal conductivity of ethylene glycol and water mixture based $\mathrm{Fe}_{3} \mathrm{O}_{4}$ nanofluid. International Communications in Heat and Mass Transfer, 49: 17-24. https://doi.org/10.1016/j.icheatmasstransfer.2013.08.02 6

[28] Pal, D. (2016). Buoyancy-driven radiative unsteady magnetohydrodynamic heat transfer over a stretching sheet with non-uniform heat source/sink. Journal of Applied Fluid Mechanics, 9(4): 1997-2007.

[29] Ishak, A., Nazar, R., Pop, I. (2007). Mixed convection on the stagnation point flow toward a vertical, continuously stretching sheet. Journal of Heat Transfer, 129(8): 10871090. https://doi.org/10.1115/1.2737482

[30] Rayapole, S.P., Jakkula, A.R. (2017). Effects of Brownian motion and thermophoresis on magneto hydrodynamics stagnation point of a nanofluid boundary layer flow on a stretching surface with variable thickness. International Journal of Current Research and Review, 9(22): 5-12. https://doi.org/10.7324/IJCRR.2017.9222

[31] Das, A.K., Chatterjee, S. (2018). Analysis of thermophoresis and Brownian motion effect in heat transfer for nanofluid immersed distribution transformer. Electrical Engineering, 100(3): 1963-1974. https://doi.org/10.1007/s00202-017-0676-2

[32] Khan, M., Malik, M.Y., Salahuddin, T., Hussian, A. (2018). Heat and mass transfer of Williamson nanofluid flow yield by an inclined Lorentz force over a nonlinear stretching sheet. Results in Physics, 8: 862-868. https://doi.org/10.1016/j.rinp.2018.01.005

[33] Acharya, N., Das, K., Kumar Kundu, P. (2016). Ramification of variable thickness on $\mathrm{MHD} \mathrm{TiO}_{2}$ and $\mathrm{Ag}$ nanofluid flow over a slendering stretching sheet using NDM. European Physical Journal Plus, 131(303): 1-16. https://doi.org/10.1140/epjp/i2016-16303-4

[34] Pal, D., Mondal, H. (2013). Influence of thermophoresis and Soret-Dufour on magnetohydrodynamic heat and mass transfer over a non-isothermal wedge with thermal radiation and Ohmic dissipation. Journal of Magnetism and Magnetic Materials, 331: 250-255. https://doi.org/10.1016/j.jmmm.2012.11.048

[35] Pakravan, H.A., Yaghoubi, M. (2011). Combined thermophoresis, Brownian motion and Dufour effects on natural convection of nanofluids. International Journal of Thermal Sciences, 50(3): 394-402. https://doi.org/10.1016/j.ijthermalsci.2010.03.0 